\title{
An optimized method for high quality DNA extraction from microalga Prototheca wickerhamii for genome sequencing
}

Tomasz Jagielski ${ }^{{ }^{* \dagger}}$, Jan Gawor ${ }^{2 \dagger}$, Zofia Bakuła ${ }^{1}$, Karolina Zuchniewicz ${ }^{2}$, Iwona Żak ${ }^{3}$ and Robert Gromadka ${ }^{2^{*}}$

\begin{abstract}
Background: The complex cell wall structure of algae often precludes efficient extraction of their genetic material. The purpose of this study was to design a next-generation sequencing-suitable DNA isolation method for unicellular, achlorophyllous, yeast-like microalgae of the genus Prototheca, the only known plant pathogens of both humans and animals. The effectiveness of the newly proposed scheme was compared with five other, previously described methods, commonly used for DNA isolation from plants and/or yeasts, available either as laboratory-developed, in-house assays, based on liquid nitrogen grinding or different enzymatic digestion, or as commercially manufactured kits.

Results: All five, previously described, isolation assays yielded DNA concentrations lower than those obtained with the new method, averaging $16.15 \pm 25.39 \mathrm{vs} 74.2 \pm 0.56 \mathrm{ng} / \mathrm{\mu L}$, respectively. The new method was also superior in terms of DNA purity, as measured by A260/A280 ( $-0.41 \pm 4.26$ vs $2.02 \pm 0.03)$, and A260/A230 (1.20 \pm 1.12 vs $1.97 \pm 0.07)$ ratios. Only the liquid nitrogen-based method yielded DNA of comparable quantity (60.96 $\pm 0.16 \mathrm{ng} /$ $\mu \mathrm{L})$ and quality $(\mathrm{A} 260 / \mathrm{A} 280=2.08 \pm 0.02 ; \mathrm{A} 260 / \mathrm{A} 230=2.23 \pm 0.26)$. Still, the new method showed higher integrity, which was best illustrated upon electrophoretic analysis. Genomic DNA of Prototheca wickerhamii POL-1 strain isolated with the protocol herein proposed was successfully sequenced on the Illumina MiSeq platform.

Conclusions: A new method for DNA isolation from Prototheca algae is described. The method, whose protocol involves glass beads pulverization and cesium chloride ( $\mathrm{CsCl}$ ) density gradient centrifugation, was demonstrated superior over the other common assays in terms of DNA quantity and quality. The method is also the first to offer the possibility of preparation of DNA template suitable for whole genome sequencing of Prototheca spp.
\end{abstract}

Keywords: DNA extraction, DNA isolation, Genome sequencing, Prototheca

\section{Background}

The genus Prototheca (Trebouxiophyceae) accommodates unicellular, achlorophyllous, yeast-like microalgae, ubiquitously distributed in the environment. Although normally saprophytic, these organisms may, under certain conditions, give rise to infections in both humans and animals. The Prototheca algae are hence the only

\footnotetext{
*Correspondence: t.jagielski@biol.uw.edu.pl; robert@ibb.waw.pl

†Tomasz Jagielski and Jan Gawor contributed equally to this work

1 Department of Applied Microbiology, Institute of Microbiology, Faculty

of Biology, University of Warsaw, I. Miecznikowa 1, 02-096 Warsaw, Poland

${ }^{2}$ DNA Sequencing and Oligonucleotides Synthesis Laboratory at the Institute of Biochemistry and Biophysics, Polish Academy of Sciences, A. Pawińskiego 5a, 02-106 Warsaw, Poland

Full list of author information is available at the end of the article
}

known plant causative agents of human and animal disease [1].

The scientific knowledge on the Prototheca algae is very limited. One of the major gaps has been a paucity of understanding of the pathobiology and mechanisms underlying the protothecal disease. For this to be revealed, a considerable amount of genetic data is required. Of particular importance would be those derived from the whole-genome sequencing (WGS) studies. Until now, however, no such reports have been published, a possible reason for this being the lack of a rapid and efficient method for high-quality genomic DNA extraction from Prototheca spp. 
Most of the protocols currently used for DNA extraction from Prototheca algae, are essentially the same as those applied for plants and/or fungi and usually exploit a variety of physical disruption methods of cell lysis, including liquid homogenization, sonication, and grinding in liquid nitrogen [2-8]. These methods, though very useful and robust for many fungal or plant species, produce little amounts of protothecal DNA, which is often highly impure and prone to shearing. Whereas such DNA can still be used as a template for single-locus PCR amplification, and subsequent sequencing, an approach commonly employed for Prototheca species- (genotype-) level identification [6, 9], it is insufficient for WGS purposes.

A combination of high concentration and high purity of DNA, with no evidence of contamination from polysaccharides, proteins or RNA, with maximally reduced fraction of fragmented and chemically degraded DNA is a prerequisite for all next-generation sequencing (NGS) technologies $[10,11]$.

The difficulty of the DNA isolation from eukaryotic microalgae has repeatedly been reported [12-15] and this has been attributed to their unique cell wall structures, whose constituents include some highly resistant biomolecules, such as algaenans, dinosporins or silica compounds [16, 17]. In Prototheca species it is sporopollenin, a complex biopolymer, which chiefly renders the algae hyper-refractory to various chemical and physical treatments used to disrupt plant cell walls $[18,19]$.

The purpose of this study was to design a next-generation sequencing-suitable DNA isolation method for Prototheca microalgae. The effectiveness of the newly proposed scheme was compared with five other, previously described methods, commonly used for DNA isolation from plants and/or yeasts available either as laboratory-developed, in-house assays or as commercially manufactured kits.

\section{Methods \\ Strain \\ Prototheca wickerhamii POL-1 strain, originally isolated at the Department of Clinical Microbiology, Children's University Hospital of Kraków, from the cerebrospinal fluid of a 6-month child with the signs of neuroinfection, which was proved to be the first case of human protothe- cosis in Poland [20], was used in this study.}

\section{Cell growth condition}

Cells of $P$. wickerhamii POL-1 strain were picked from a single colony on Yeast-Peptone-Dextrose (YPD) agar (Sigma, Saint Louis, USA) and grown in a $100 \mathrm{~mL}$ volume of YPD broth for $72 \mathrm{~h}$ at $37^{\circ} \mathrm{C}$ with shaking $(200 \mathrm{rpm})$ until the optical density at A600 reached ca. 5.0 (ca. $6.5 \times 10^{5} \mathrm{CFU}$ ).

\section{Genomic DNA extraction protocols}

Six DNA extraction protocols were evaluated in this study. DNA was isolated in triplicate with each protocol. The first experimental steps were always the same and aimed at separating the algal cells from the medium. Shortly, a total volume of $10 \mathrm{~mL}$ of liquid culture was centrifuged (10 min, $5000 \mathrm{rpm}, \mathrm{RT})$, and the obtained pellet was suspended in $1 \mathrm{~mL}$ of Tris-EDTA (TE; $10 \mathrm{mM}$ Tris- $\mathrm{HCl} \mathrm{pH} \mathrm{7.6,} 0.1 \mathrm{mM}$ EDTA). This was repeated twice to ensure complete removal of growth medium. At the end, washed cell pellet was suspended in a proper buffer, depending on the chosen protocol's specification.

\section{Extraction with grinding in liquid nitrogen (LN)}

First extraction method was performed as described by van Burik et al. [7]. Briefly, the algal cells, suspended in TE buffer, were ground to a fine powder, by using an autoclaved, pre-chilled mortar and pestle. The powdered sample was resuspended in $600 \mu \mathrm{L}$ of cetyltrimethylammonium bromide (CTAB) extraction buffer (1\% CTAB (Sigma, Saint Louis, USA), 1.4 M NaCl, $100 \mathrm{mM}$ Tris $\mathrm{pH}$ 8.0, $20 \mathrm{mM}$ EDTA), transferred to a 2-mL microcentrifuge tube and incubated on ice for $1 \mathrm{~h}$. DNA was further extracted using phenol-chloroform-isoamyl alcohol (Phe/Chl/IAA, 25:24:1) (Sigma, Saint Louis, USA) followed by isopropanol DNA precipitation. The obtained pellet was resuspended in $100 \mu \mathrm{L}$ TE buffer with RNAse A (50 $\mu \mathrm{g} / \mathrm{mL}$, Sigma, Saint Louis, USA), and after centrifugation (5 min, 14,000 rpm, RT), the cellular debris was removed, while clear supernatant was transferred to a new tube.

\section{Extraction with grinding in CTAB (C)}

Second extraction method was that described by Doyle [8]. The algal pellet was ground in pre-warmed $\left(60{ }^{\circ} \mathrm{C}\right)$ CTAB isolation buffer (2\% CTAB (Sigma, Saint Louis, USA), 1.4 M NaCl, $100 \mathrm{mM}$ Tris pH 8.0, $20 \mathrm{mM}$ EDTA). The mixture was then transferred to a $2-\mathrm{mL}$ microcentrifuge tube and incubated at $60{ }^{\circ} \mathrm{C}$ for $1 \mathrm{~h}$. DNA was extracted once with chloroform-isoamyl alcohol (Chl/ IAA, 24:1) (Sigma, Saint Louis, USA) and precipitated with two volumes of isopropanol. The obtained pellet was washed with $70 \% \mathrm{EtOH}$, dried, and dissolved in $100 \mu \mathrm{L}$ TE buffer with RNAse A ( $50 \mu \mathrm{g} / \mathrm{mL}$, Sigma, Saint Louis, USA).

\section{Extraction by enzyme cocktail (EC)}

Another isolation method was based on a CTAB protocol, previously used for DNA isolation from Chlorella variabilis NC64A [21], with an additional cell wall digestion step with polysaccharide-degrading enzymes, suitable for Prototheca spp. [22]. Here, the algal cells were resuspended in $900 \mu \mathrm{L}$ of TE buffer and then $100 \mu \mathrm{L}$ of 
enzyme cocktail containing lyticase $(100 \mu \mathrm{g} / \mathrm{mL}$, Sigma, Saint Louis, USA), cellulase Onozuka RS $(1 \mathrm{mg} / \mathrm{mL}$, Yakult Pharmaceutical Industry, Tokyo, Japan), pectolyase ( $1 \mathrm{mg} / \mathrm{mL}$, Sigma, Saint Louis, USA), and pectinase ( $1 \mathrm{mg} / \mathrm{mL}$, Sigma, Saint Louis, USA) was added. The cell suspension was incubated at $37^{\circ} \mathrm{C}$ for $3 \mathrm{~h}$. Cell lysis was continued by addition of $100 \mu \mathrm{L}$ of $10 \%$ SDS and Proteinase K (10 $\mu \mathrm{g} / \mathrm{mL}$, Sigma, Saint Louis, USA), followed by incubation at $56^{\circ} \mathrm{C}$ for $1 \mathrm{~h}$. After cell lysis, $200 \mu \mathrm{L}$ of $5 \mathrm{M}$ $\mathrm{NaCl}$ was added to the sample and mixed thoroughly. Afterwards, $160 \mu \mathrm{L}$ of $\mathrm{CTAB}$, prewarmed to $65{ }^{\circ} \mathrm{C}$, was added, followed by $10 \mathrm{~min}$ of incubation at $65{ }^{\circ} \mathrm{C}$. The lysate was then extracted four times with an equal amount of Phe/Chl/IAA (25:24:1) until the interface was clear. DNA was precipitated by addition of 0.7 volume of isopropanol and centrifugation (20 min, 14,000 rpm, RT). DNA pellet was washed once with $1 \mathrm{~mL}$ of $70 \%$ ethanol, air-dried, dissolved in $200 \mu \mathrm{L}$ of TE buffer with RNase A $(50 \mu \mathrm{g} / \mathrm{mL})$, and incubated at $37^{\circ} \mathrm{C}$ for $30 \mathrm{~min}$ with shaking. Samples were then spun in a microcentrifuge $(5 \mathrm{~min}$, $14,000 \mathrm{rpm}, \mathrm{RT}$ ), and clear supernatant was transferred to a new tube.

\section{Extraction with commercial kits (K1 and K2)}

Two commercially available kits, designed for rapid purification of genomic DNA, based on specific buffer formulations and DNA-binding silica membrane columns, were tested, namely GeneMATRIX Bacterial \& Yeast Genomic DNA Purification Kit $\left(E u r X^{\circledR}\right.$, Gdańsk, Poland), in combination with lyticase $(100 \mu \mathrm{g} / \mathrm{mL})$ and $\beta$-mercaptoethanol ( $\beta$-ME, $1 \mu \mathrm{L} / \mathrm{mL}$ ) (Sigma, Saint Louis, USA) (K1) and GeneMATRIX Plant \& Fungi DNA Purification Kit (EurX ${ }^{\circledR}$, Gdańsk, Poland) (K2). When using both kits, all steps were performed strictly in accordance with instructions provided by the manufacturer.

\section{Extraction with glass beads: a new protocol (N)}

The cell pellet from culture medium was suspended in $750 \mu \mathrm{L}$ of an extraction buffer (2\% Triton-X100, $1 \%$ SDS, $100 \mathrm{mM} \mathrm{NaCl}, 10 \mathrm{mM}$ Tris- $\mathrm{HCl} \mathrm{pH} \mathrm{8.0,} 1 \mathrm{mM}$ EDTA) [7], and the suspension was transferred into 2-mL microcentrifuge tube. Lysis of the algae was achieved by pulverization with $0.4-0.6-\mathrm{mm}$ diameter glass beads (Sartorius AG, Göttingen, Germany), in a 1:1 ratio, in a tissue lyser (TissueLyser II; Qiagen, Hilden, Germany) at $20 \mathrm{~Hz}$ for $15 \mathrm{~min}$. The sample was then transferred into a $5-\mathrm{mL}$ microcentrifuge tube. The glass beads were washed two times with $500 \mu \mathrm{L}$ of an extraction buffer, and the washes were pooled and added to the homogenate, so that its final volume was ca. $2.5 \mathrm{~mL}$. Cell lysis was continued by adding Proteinase $\mathrm{K}(160 \mu \mathrm{g} / \mathrm{mL})$ and incubation at $56{ }^{\circ} \mathrm{C}$ for $1 \mathrm{~h}$. After that time, $500 \mu \mathrm{L}$ of $5 \mathrm{M} \mathrm{NaCl}$ was added and mixed thoroughly. Next, $400 \mu \mathrm{L}$ of CTAB, prewarmed to $65{ }^{\circ} \mathrm{C}$, was added followed by $10 \mathrm{~min}$ of incubation at $65{ }^{\circ} \mathrm{C}$. The lysate was then extracted with an equal volume of Phe/Chl/IAA (24:24:1), repeated four times until no protein interphase could be seen. DNA was precipitated with 0.7 volume of isopropanol, followed by centrifugation ( $20 \mathrm{~min}, 14,000 \mathrm{rpm}, \mathrm{RT})$, and washing with $1 \mathrm{~mL}$ of $70 \%$ ethanol. The resulting pellet was air-dried and resuspended in $200 \mu \mathrm{L}$ of TE buffer with RNAse A $(50 \mu \mathrm{g} / \mathrm{mL})$. Following an incubation at $37{ }^{\circ} \mathrm{C}$ with gently shaking for $30 \mathrm{~min}$, DNA was centrifuged again ( $5 \mathrm{~min}, 14,000 \mathrm{rpm}, \mathrm{RT}$ ), and the clear supernatant was collected in a new tube.

\section{Optional sample clean-up prior to DNA concentration measurements}

To all the in-house methods (LN, EC, N) an extra step was added to remove any residual ribonucleotides, proteins, and other possible contaminants which might interfere with sample quality. This was achieved by adding to the DNA precipitate, after RNAse treatment, an equal volume of Chl/IAA (24:1) (Sigma, Saint Louis, USA). Once centrifuged (5 min, 14,000 rpm, RT), the supernatant was taken for re-precipitation of DNA with 0.7 volume of isopropanol. This was followed by centrifugation (15 min, 14,000 rpm, RT), washing with $500 \mu \mathrm{L}$ of $70 \%$ ethanol, air-drying, and re-suspension in $100 \mu \mathrm{L}$ of TE buffer.

\section{Nuclear DNA purification}

DNA sample obtained with the $\mathrm{N}$ method was used in this procedure. To separate nuclear DNA from mitochondrial and plastid DNA, cesium chloride $(\mathrm{CsCl})$ density gradient ultracentrifugation was performed, essentially as described before [23]. Shortly, DNA sample was transferred to a centrifuge tube, containing $8.6 \mathrm{~g}$ of $\mathrm{CsCl}$ and $1 \mathrm{~mL}$ of ethidium bromide $(10 \mu \mathrm{g} /$ $\mathrm{mL}$, Sigma, Saint Louis, USA) and filled up with TE buffer to a final volume of $8 \mathrm{~mL}$. After centrifugation (5 min, 10,000 rpm, RT), samples were decantated to a new tube and ultracentrifuged $\left(48 \mathrm{~h}, 45,000 \mathrm{rpm}, 15^{\circ} \mathrm{C}\right.$, Beckman, Ti50 rotor, Indianapolis, USA). After the ultracentrifugation, the brighter upper band, expected to represent nuclear DNA fraction, was collected with a pipette under UV transilluminator. To remove $\mathrm{CsCl}$ from DNA solution a dialysis was carried out in cellulose membranes $(\mathrm{MWCO}=140,000$; Sigma Saint Louis, USA) at $4{ }^{\circ} \mathrm{C}$ for $20 \mathrm{~h}$ with one TE buffer change. After dialysis samples were collected and concentrated using the Amicon Ultra $0.5 \mathrm{~mL} 30 \mathrm{~K}$ columns in accordance to the manufacturer's instructions (Merck Millipore, Darmstadt, Germany). 


\section{DNA concentration and purity}

For each extraction procedure, the quantity and purity of template DNA was assessed based on the absorbance readings at 230,260 , and $280 \mathrm{~nm}$, and calculated 260:280 and 260:230 ratios, using a PicoDrop spectrophotometer (PicoDrop Ltd, Hinxton, UK). Concentration of the genomic DNA was estimated fluorometrically using the High Sensitivity DNA kit and Qubit 2.0 fluorometer (Thermo Fisher Scientific, Waltham, USA). Each time $1 \mu \mathrm{L}$ (fluorescence) or $2 \mu \mathrm{L}$ (absorbance) of DNA sample (or TE buffer as a blank solution) was used. All measurements were done in duplicate.

\section{DNA integrity}

The integrity of genomic DNA, isolated with five tested methods, was assessed by standard electrophoresis, pulsed field gel electrophoresis (PFGE) and field-inversion gel electrophoresis (FIGE). Firstly, DNA samples were resolved electrophoretically on a $1 \%$ agarose gel. Secondly, samples whose DNA concentrations were more than $2 \mathrm{ng} / \mu \mathrm{L}$ (methods LN, K1, K2, N) were subjected to PFGE and FIGE analysis to visualize smaller (>45 kb) and larger $(<45 \mathrm{~kb})$ DNA fragments, respectively. Both these analyses were performed with a CHEF Mapper system (BioRad, Hercules, USA), following the manual instructions [24], on 1.0\% Pulsed Field Certified Agarose gels (BioRad, Hercules, USA) in $0.5 \times$ Tris-Borate EDTA (TBE; $40 \mathrm{mM}$ Tris-HCl pH 8.3, $45 \mathrm{mM}$ boric acid, $1 \mathrm{mM}$ EDTA) pre-chilled to $14{ }^{\circ} \mathrm{C}$. PFGE was run for $18 \mathrm{~h}$ at an angle of $120^{\circ}$, with an initial switching time of $0.35 \mathrm{~s}$ and a final switching time of $8.53 \mathrm{~s}$, at $6 \mathrm{~V} / \mathrm{cm}$. For FIGE analysis, 24-h run was used with a switch time logarithmically ramping from 0.22 to $0.92 \mathrm{~s}$, and with a ramp factor of 0.357 (21\%). Forward and reverse voltage gradients were $9 \mathrm{~V} / \mathrm{cm}(300 \mathrm{~V})$ and $6 \mathrm{~V} / \mathrm{cm}(200 \mathrm{~V})$, respectively. Gels were stained with ethidium bromide $(10 \mu \mathrm{g} / \mathrm{mL})$ and visualized using UV transilluminator.

\section{Quality assessment of extracted DNA}

To assess the quality and purity of nuclear DNA extracted with a new, optimized protocol, and to evaluate its usefulness for genome sequencing, the WGS was performed with the Illumina MiSeq platform (Illumina, San Diego, USA). This was done for two genomic DNA samples obtained by the $\mathrm{N}$ method with and without $\mathrm{CsCl}$ ultracentrifugation to ensure that this step is crucial for separation of nuclear from organellar DNA. The pair-end sequencing library construction was performed with $1 \mu \mathrm{g}$ of post-nebulized DNA extract and the KAPA Library Preparation Kit reagents (KAPA Biosystems, Wilmington, USA), according to manufacturer's instructions. The libraries were quality checked on an agarose (1.5\%) gel, pooled and sequenced on a MiSeq instrument using the
MiSeq reagent Kit v3 (600 cycle) chemistry (Illumina, San Diego, USA).

Once obtained, sequence reads were quality filtered using FastaX toolkit [25], and the remaining sequencing adaptors were removed by Cutadapt [26]. Nuclear, mitochondrial, and plastid genomes of $P$. wickerhamii POL-1 strain were entirely sequenced in the course of the Polish P. wickerhamii WGS project (manuscript in preparation). All the bioinformatic manipulations were done using the CLCBio Genomic Workbench NGS pipeline [27].

To estimate separation of nuclear DNA from organellar DNA, one million of Illumina sequencing paired reads (2 million of sequence reads) were randomly subsampled from $P$. wickerhamii POL-1 strain library dataset. The sequences were searched against mitochondrial and plastid genomes of $P$. wickerhamii POL-1.

The read quality distribution graph was generated using CLC Bio Genomic Workbench software (Version 9.0; Qiagen, Hilden, Germany).

\section{Results and discussion \\ DNA concentration and quality}

Basic DNA quality measures, for each extraction method tested, are listed in Table 1. Of the six methods under the study, the efficiency of three (EC, K1, and K2) was low with DNA concentrations less than $4 \mathrm{ng} / \mu \mathrm{L}$, as evidenced by fluorometry. The enzymatic method (EC) performed the worst both in terms of DNA quantity $(1.6 \pm 0.01 \mathrm{ng} / \mu \mathrm{L})$ as well as A260:280 $(-7.97 \pm 19.25)$ and A260:230 (0.15 \pm 0.02$)$ ratios. The absorbance ratios were also far from satisfactory (A260:280 $=1.32 \pm 0.50$ and $0.70 \pm 0.29, \mathrm{~A} 260: 230=0.51 \pm 0.07$ and $0.53 \pm 0.17$ for K1 and K2, respectively) in case of DNA extraction by using silica membrane-based spin columns (K1 and K2). The low A260:280 ratios may either be due to heavy protein contamination or residual phenol associated with the

Table 1 Comparison of five different DNA extraction methods for P. wickerhamii POL-1 strain in terms of purity and yield

\begin{tabular}{lccc}
\hline Method & Absorbance & \multicolumn{1}{c}{$\begin{array}{l}\text { Concentration (ng/ } \\
\text { ML) }\end{array}$} \\
\cline { 2 - 3 } & $\mathbf{2 6 0 : 2 8 0}$ & $\mathbf{2 6 0 : 2 3 0}$ & \\
\hline Liquid nitrogen (LN) & $2.08 \pm 0.02$ & $2.23 \pm 0.26$ & $60.96 \pm 0.16$ \\
CTAB (C) & $1.84 \pm 0.03$ & $2.59 \pm 0.02$ & $12.07 \pm 0.7$ \\
$\begin{array}{c}\text { Enzyme cocktail } \\
\text { (EC) }\end{array}$ & $-7.97 \pm 19.25$ & $0.15 \pm 0.02$ & $1.6 \pm 0.01$ \\
$\begin{array}{c}\text { GeneMATRIX Bacte- } \\
\text { rial \& Yeast (K1) }\end{array}$ & $1.32 \pm 0.50$ & $0.51 \pm 0.07$ & $2.28 \pm 0$ \\
$\begin{array}{c}\text { GeneMATRIX Plant } \\
\text { \& Fungi (K2) }\end{array}$ & $0.70 \pm 0.29$ & $0.53 \pm 0.17$ & $3.85 \pm 0.02$ \\
$\begin{array}{c}\text { Newly designed } \\
\text { protocol (N) }\end{array}$ & $2.02 \pm 0.03$ & $1.97 \pm 0.07$ & $74.2 \pm 0.56$ \\
\hline
\end{tabular}


extraction protocol. Whereas, the low A260:230 ratios may either indicate residual phenol or carbohydrate carryover, a problem commonly encountered upon DNA isolation from plants [28]. For samples extracted with the LN, C, and N methods, the A260:280 ratios fell within the range of 2.06-2.1, 1.81-1.87, and 1.99-2.05, respectively, whereas the A260:230 ratios were within the range of and $1.97-2.49,2.57-2.61$, and $1.92-2.05$ respectively. These values are consistent with the absence of proteins and other organic contaminants.

Although the purity indicators of the three methods (LN, C, and N) were quite the same, the $\mathrm{N}$ method yielded DNA of higher concentrations $(74.2 \pm 0.56$ vs $12.07 \pm 0.7$ vs $60.96 \pm 0.16 \mathrm{ng} / \mu \mathrm{L})$.

Standard electrophoresis of DNA extracts showed the best results for the $\mathrm{N}$ method, both in terms of DNA yield and integrity. Whereas methods EC, K1, K2, and $C$ generated clearly smaller DNA amounts, method LN produced DNA less intact and more sheared (Fig. 1a).

To further inspect the integrity of DNA samples obtained with different extraction methods, PFGE and FIGE analyses were performed. PFGE analysis revealed that all the DNA templates were sheared during the extraction procedure. Yet the $\mathrm{N}$ method resulted in somewhat narrower fragment length distribution, with slightly greater contribution of large fragments compared to the LN method (Fig. 1b).

DNA isolation methods generating high molecular weight DNA fragments have been considered more suitable for second generation sequencing technology such as Illumina and third-generation sequencing technologies capable of producing long reads, such as Pacific Biosciences single-molecule real-time (SMRT) or Oxford Nanopore sequencing [29, 30]. Long DNA fragments are crucial for high quality libraries preparation and further efficient genome assembly using long reads [31].
Similar observations were concluded with the FIGE analysis, i.e. low DNA concentration with a length distribution weighted more towards shorter fragments (K1 and K2) and high DNA concentration with much broader fragment length distribution ( $\mathrm{LN}$ and $\mathrm{N}$ ) (Fig. 1c). As

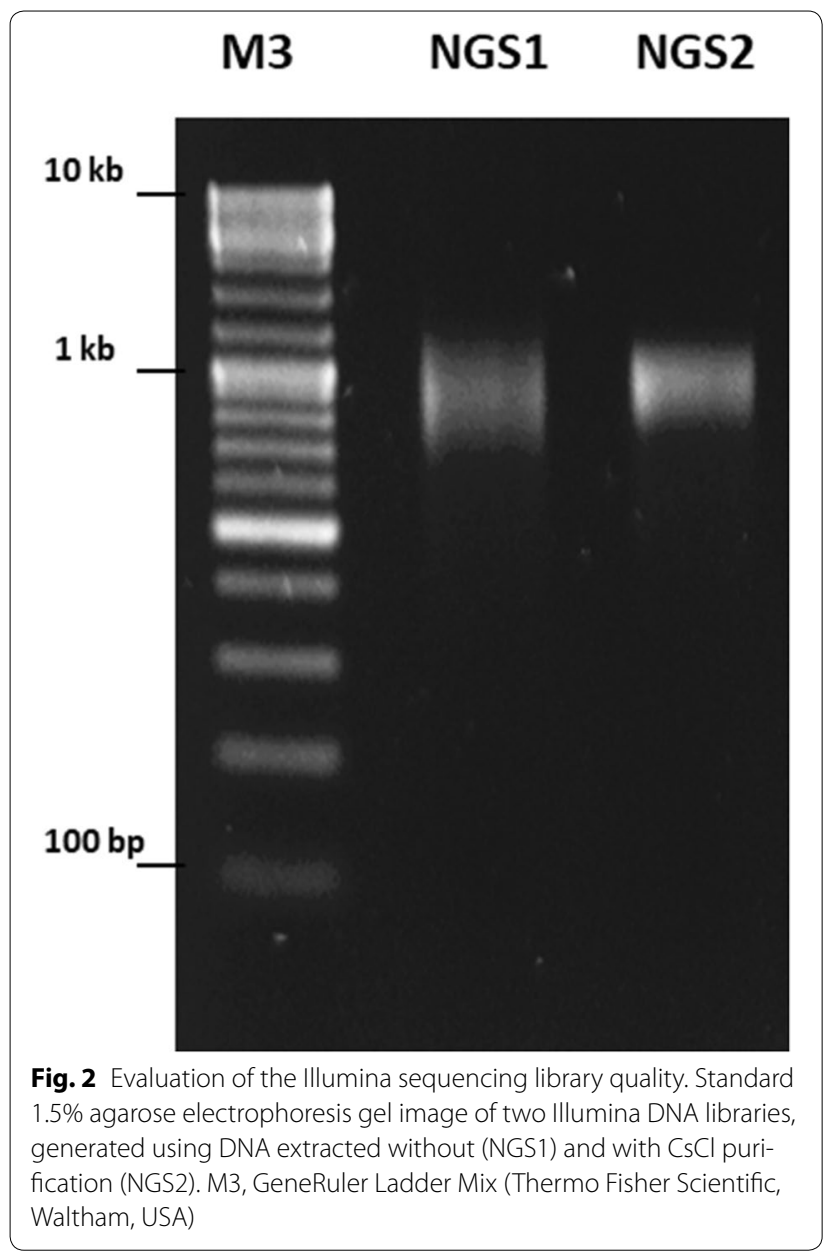

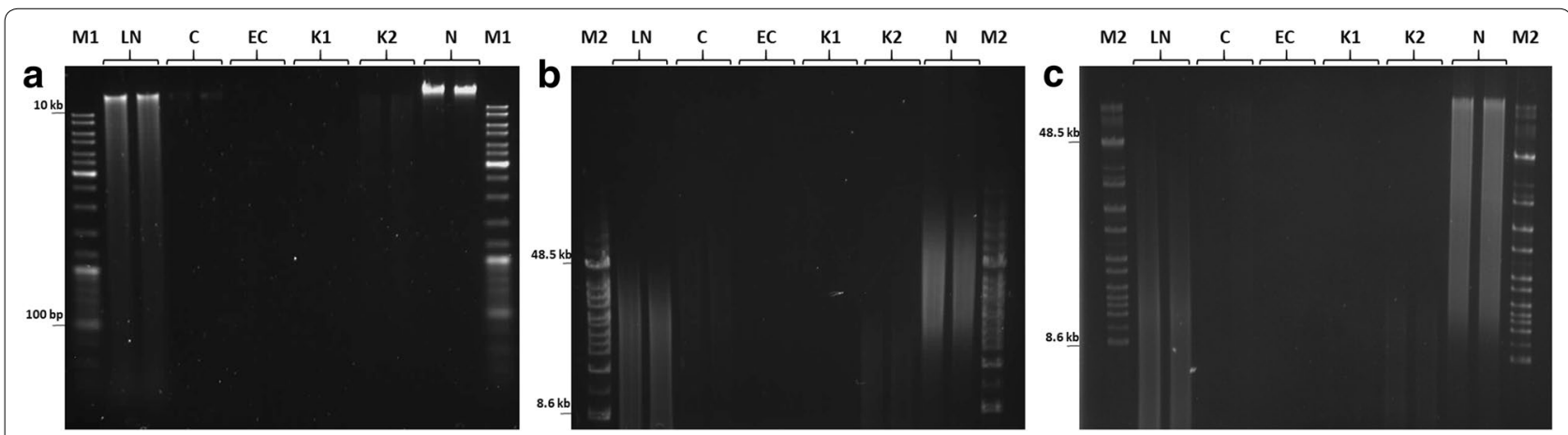

Fig. 1 Evaluation of DNA integrity. Standard electrophoresis (a), PFGE (b), and FIGE (c) analysis of genomic DNA (10 $\mu$ L) isolated by different methods: liquid- (LN), CTAB- (C), enzyme cocktail (EC)-based, commercial kits (K1 and K2), and glass beads pulverization-based, new protocol (N). M1, GeneRuler 1 kb DNA Ladder (Thermo Fisher Scientific, Waltham, USA), M2, CHEF DNA Size Standards - 8-48 kb (BioRad, Hercules, USA) 
Table 2 Summary of $P$. wickerhamii POL-1 genomic DNA sequencing results

\begin{tabular}{llrr}
\hline Sample & Amount of DNA for library preparation $\mathbf{( n g )}$ & Sequencing reads-total & Sequencing bases-total \\
\hline With CsCl & 1000 & $2,342,210$ & $703,254,704$ \\
Without $\mathrm{CsCl}$ & 1000 & $10,173,050$ & $3,033,748,450$ \\
\hline
\end{tabular}

Table 3 A total number of reads unmapped and mapped to mitochondrial and plastid genome sequence of the $P$. wickerhamii POL-1 strain

\begin{tabular}{|c|c|c|c|}
\hline \multirow[t]{2}{*}{ Sample } & \multicolumn{3}{|l|}{ Reads count } \\
\hline & Unmapped-nuclear DNA & Mapped (mtDNA + ptDNA) & Mapped \% \\
\hline With $\mathrm{CsCl}$ & $1,866,137$ & $133,863(56,536+77,327)$ & 6.69 \\
\hline Without $\mathrm{CsCl}$ & $1,992,445$ & $7555(2686+4869)$ & 0.38 \\
\hline
\end{tabular}

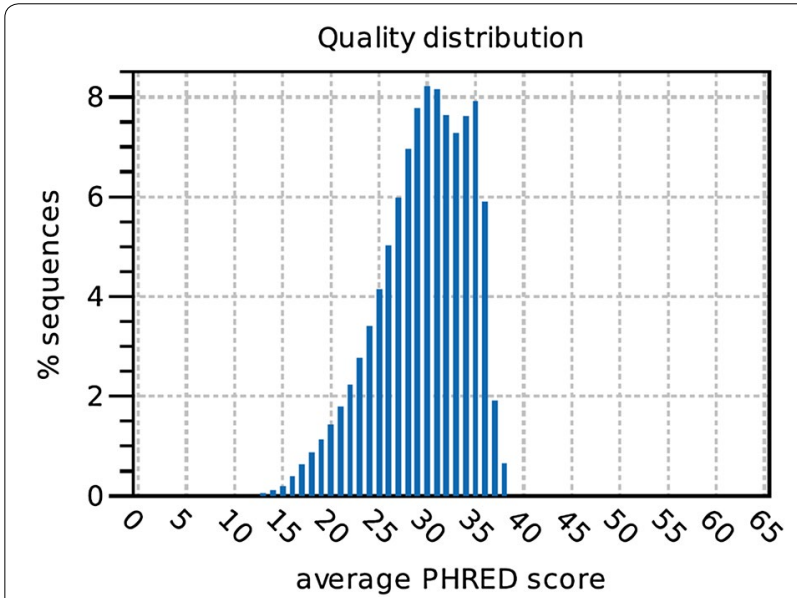

Fig. 3 The quality of Prototheca wickerhamii POL-1 genomic DNA sequence. The $x$-axis represents the PHRED quality score and the $y$-axis represents the percentage of sequences with a quality score, normalized to the total number of sequences

repeatedly argued, the higher average molecular weight of the fragments, clearly seen on electropherograms, the better is the quality of the genomic template $[32,33]$.

\section{NGS sequencing quality}

Libraries for $P$. wickerhamii POL-1 genomic DNA extracted with a newly designed $(\mathrm{N})$ protocol, with and without $\mathrm{CsCl}$ ultracentrifugation step, were constructed (Fig. 2) and successfully sequenced on Illumina MiSeq platform with an average insert size of 760 and $750 \mathrm{bp}$ and yielding 2,342,210 and 10,173,050 reads, respectively (Table 2). The ultracentrifugation step was demonstrated advantageous for removal of the extranuclear DNA, as evidenced by reduced number of reads mapped to mitochondrial and plastid genome sequence of the P. wickerhamii POL-1 strain (Table 3). The number of sequences aligned to mtDNA and ptDNA after additional purification decreased from 56,536 to 2686 and from 77,327 to 4869 , respectively. The overall number of reads mapped to organellar genomes decreased by nearly 18 times (from 6.69 to $0.38 \%$ ) when the $\mathrm{CsCl}$ gradient step was applied.

To measure the quality of the identification of the nucleotide bases generated by sequencing, PHRED quality score was estimated for protothecal DNA samples extracted with $\mathrm{CsCl}$ ultracentrifugation (Fig. 3). Average PHRED score was calculated at the level of 30 which implies high confidence in the quality of DNA submitted (with base call accuracy of 99.9\%) [34].

The genome of the $P$. wickerhamii POL-1 strain was entirely sequenced in the course of the Polish $P$. wickerhamii WGS project. The sequencing yielded 2860 scaffolds with the total assembly size of 29 Mbps (manuscript under preparation).

The reason for which the NGS was performed only on DNA isolated with the $\mathrm{N}$ method, and not with the others, including the "LN" method was not only better parameters for DNA quantity and purity (Table 1), but also its higher integrity, as assessed by electrophoretic methods, especially PFGE and standard electrophoresis. As shown in Fig. 1, the $\mathrm{N}$ method produced DNA template less sheared and of narrower fragment length distribution. This is of particular notice that the $\mathrm{N}$ method yielded more larger fragments compared with the LN method. This can be seen on inspecting Fig. 1, with a clear shift towards fragments of higher molecular weight or a height of large DNA fragments having greater intensities, respectively; the central molecular size of the fragments' range was ca. 33.5-38.4 kb for the LN method, and ca. $48.5 \mathrm{~kb}$ for the $\mathrm{N}$ method.

Long DNA fragments are mandatory for high quality libraries preparation for NGS technologies and further efficient de novo genome assembly especially with long reads. 
All this argued for the superiority of the $\mathrm{N}$ method over the other ones, including the LN method, and guided our decision of using this particular method $(\mathrm{N})$ in further experimental steps, such as the $\mathrm{CsCl}$ purification, and finally sequencing.

\section{Conclusions}

In the present study, for the first time, an efficient and reliable procedure of protothecal DNA extraction for whole-genome sequencing and large-scale genotyping studies was described. The protocol herein proposed incorporates some key technological solutions from previously described assays of plant and fungal DNA isolation, and involves a three-pronged approach for whole cell lysis, i.e. mechanical (glass bead pulverization), surfactant-based (Triton-X100, SDS, and CTAB treatment), and enzymatic (Proteinase $\mathrm{K}$ treatment) disruption methods. An important step in the protocol is the $\mathrm{CsCl}$ density gradient ultracentrifugation allowing for separation of nuclear DNA from extranuclear (organellar) DNA. To the best of authors' knowledge, a method combining all these components has never been attempted to isolate genomic DNA from either microalgae or any other plant species.

The method here reported represents a considerable improvement over the present methods of DNA isolation from the cell-walled eukaryotes. The key advantages are a good yield and high quality (purity and integrity) of DNA, affording different molecular genotyping technologies, including NGS. Perhaps the only drawback of the method is that the procedure is quite time-consuming, with a turnaround time of 3-4 days before the specimen can achieve a ready-to-use form.

One may argue why did we not apply some other, already existing protocols of DNA extraction from microalgae. For instance, in the early 2000s, the nucleotide sequence of the $P$. wickerhamii ptDNA was determined by using, for DNA isolation, a liquid nitrogen-based method [35]. More recently, Tourasse et al. have reported the complete mitochondrial genome sequence of Lobosphaera (Parietochloris) incisa, an oleaginous unicellular green alga belonging to the class Trebouxiophyceae, the same that the Prototheca genus is affiliated with. Here, DNA was extracted following the standard CTAB DNA extraction protocol, whose original description was provided 30 years ago [36]. Both these methods, under the $\mathrm{LN}$ and $\mathrm{C}$ designations, respectively, were tested in our study. However, in terms of at least DNA concentration and DNA size distribution, which are among the key parameters for NGS, both these methods were inferior to our newly-developed $\mathrm{N}$ method. At this point, it is worth considering two issues. First, a method of DNA isolation, useful for some species, may not be equally or at all effective for other, even closely-related species. This may be due to even discrete differences in the cell wall composition, especially the content and/or distribution of chemically refractory compounds, such as sporopollenin, a distinctive constituent of the protothecal cell wall. Second, a method of DNA isolation, which allows for sequencing of the extrachromosomal DNA (ptDNA and/or mtDNA) may not be suitable for whole-genome sequencing [37]. It is remarkable that with a plethora of DNA extraction methods available, never has the genomic DNA, other than organellar, been sequenced in Prototheca spp.

Since the method here proposed is the first to offer the possibility of preparation of protothecal DNA template suitable for WGS, it paves the way for large-scale investigations into genomics and proteomics of the Prototheca spp., and possibly other microalgae and plants.

\section{Authors' contributions}

TJ: study design and supervision, writing of manuscript, critical revision; JG: study design, acquisition of data (performing methods $L N$, EC, ND, spectrophotometric and fluorometric analysis, genome sequencing), writing of manuscript; ZB: acquisition of data (performing methods K1, K2, CsCl gradient ultracentrifugation, electrophoresis, PFGE, FIGE), drafting of manuscript; KZ: acquisition of data (performing methods LN, EC, ND), Illumina library preparation, genome sequencing; IZ: Prototheca wickerhamii strain isolation and culture; RG: study design, analysis and interpretation of data, drafting of manuscript, critical revision. All authors read and approved the final manuscript.

\section{Author details}

${ }^{1}$ Department of Applied Microbiology, Institute of Microbiology, Faculty of Biology, University of Warsaw, I. Miecznikowa 1, 02-096 Warsaw, Poland. ${ }^{2}$ DNA Sequencing and Oligonucleotides Synthesis Laboratory at the Institute of Biochemistry and Biophysics, Polish Academy of Sciences, A. Pawińskiego 5a, 02-106 Warsaw, Poland. ${ }^{3}$ Department of Clinical Microbiology, Children's University Hospital of Cracow, Kraków, Poland.

\section{Acknowledgements}

Not applicable.

Competing interests

The authors declare that they have no competing interests.

Availability of data and materials

All data generated or analyzed during this study are included in this published article.

Consent for publication

Not applicable.

Ethics approval and consent to participate

Not applicable.

Funding

The study was financed by the National Science Centre grants «PRELUDIUM» (2013/09/N/NZ2/00248) and «SONATA» (2014/15/D/NZ7/01797).

\section{Publisher's Note}

Springer Nature remains neutral with regard to jurisdictional claims in published maps and institutional affiliations.

Received: 21 March 2017 Accepted: 19 September 2017

Published online: 03 October 2017 


\section{References}

1. Jagielski T, Lagneau PE. Protothecosis. A pseudofungal infection. J Mycol Méd. 2007:17:261-70.

2. Bozzo G, Bonerba E, Di Pinto A, Bolzoni G, Ceci E, Mottola A, et al. Occurrence of Prototheca spp. in cow milk samples. New Microbiol. 2014;37:459-64

3. Gao J, Hou RG, Zhang HQ, He JZ, Li SM, Su JL, Han B. A novel DNA extraction and duplex polymerase chain reaction assay for the rapid detection of Prototheca zopfii genotype 2 in milk. Lett Appl Microbiol. 2011;53:278-82

4. Jagielski T, Lassa H, Ahrholdt J, Roesler U, Malinowski E. Molecular characterization of Polish Prototheca zopfii mastitis isolates and first isolation of Prototheca blaschkeae in Poland. Pol J Vet Sci. 2010;4:725-9.

5. Ricchi M, Cammi G, Garbarino CA, Buzzini P, Belletti GL, Arrigoni N. A rapid real-time PCR/DNA resolution melting method to identify Prototheca species. J Appl Microbiol. 2011;110:27-34.

6. Roesler U, Scholz H, Hensel A. Immunodiagnostic identification of dairy cows infected with Prototheca zopfii at various clinical stages and discrimination between infected and uninfected cows. J Clin Microbiol. 2001:39:539-43.

7. van Burik JA, Schreckhise RW, White TC, Bowden RA, Myerson D. Comparison of six extraction techniques for isolation of DNA from filamentous fungi. Med Mycol. 1998;36:299-303.

8. Doyle J. DNA protocols for plants. In: Hewitt GM, Johnston AWB, Young JPW, editors. Molecular techniques in taxonomy. NATO ASI Series (Series $\mathrm{H}$ : Cell Biology), vol. 57. Berlin: Springer; 1991.

9. Jagielski T, Lassa H, Ahrholdt J, Malinowski E, Roesler U. Genotyping of bovine Prototheca mastitis isolates from Poland. Vet Microbiol. 2011;149:283-7.

10. Linnarsson S. Recent advances in DNA sequencing methods-general principles of sample preparation. Exp Cell Res. 2010;316:1339-43.

11. Healey A, Furtado A, Cooper T, Henry RJ. Protocol: a simple method for extracting next-generation sequencing quality genomic DNA from recalcitrant plant species. Plant Methods. 2014;10:21.

12. Maneeruttanarungroj $C$, Incharoensakdi A. Rapid method for DNA isolation from a tough cell wall green alga Tetraspora sp. CU2551. World J Microbiol Biotechnol. 2016;32:99.

13. Tear CJY, Lim C, Wu J, Zhao H. Accumulated lipids rather than the rigid cell walls impede the extraction of genetic materials for effective colony PCRs in Chlorella vulgaris. Microb Cell Fact. 2013;12:106.

14. Eland LE, Davenport R, Mota CR. Evaluation of DNA extraction methods for freshwater eukaryotic microalgae. Water Res. 2012;15:5355-64.

15. Kim BH, Ramanan R, Cho DH, Choi GC, La HJ, Ahn CY, et al. Simple, rapid and cost-effective method for high quality nucleic acids extraction from different strains of Botryococcus braunii. PLoS ONE. 2012. doi:10.1371/ journal.pone.0037770.

16. Domozych DS, Ciancia M, Fangel JU, Mikkelsen DM, Ulvskov P, Willats WGT. The cell walls of green algae: a journey through evolution and diversity. Front Plant Sci. 2012;3:82.

17. Siegel BZ, Siegel SM. The chemical composition of algal cell walls. CRC Crit Rev Microbiol. 1973:3:1-26.

18. He X, Dai J, Wu Q. Identification of sporopollenin as the outer layer of cell wall in microalga Chlorella protothecoides. Front Microbiol. 2016:7:1047.

19. Lassa H, Jagielski T, Malinowski E. Effect of different heat treatments and disinfectants on the survival of Prototheca zopfii. Mycopathologia. 2010;171:177-82

20. Żak I, Jagielski T, Kwiatkowski S, Bielecki J. Prototheca wickerhamii as a cause of neuroinfection in a child with congenital hydrocephalus. First case of human protothecosis in Poland. Diagn Microbiol Infect Dis. 2012;74:186-9.
21. Blanc G, Duncan G, Agarkova I, Borodovsky M, Gurnon J, Kuo A, et al. The Chlorella variabilis NC64A genome reveals adaptation to photosymbiosis, coevolution with viruses, and cryptic sex. Plant Cell. 2010;22:2943-55.

22. Suzuki T. Electrophoretic separation of chromosomes in an achlorophyllous microalga, Prototheca zopfii. J Tokyo Univ Nat Sci. 2006;50:13-6.

23. Sambrook J, Russell DW. Isolation and quantification of DNA. In: Inglis J, Boyle A, Gann A, editors. Molecular cloning - a laboratory manual. Cold Spring Harbor, NY: Cold Spring Harbor Laboratory Press; 2001

24. CHEF Mapper ${ }^{\circledR}$ XA Pulsed Field Electrophoresis System. In: Instruction Manual and Application Guide Rev E. http://www.mbl.edu/jbpc/ files/2014/05/CHEFMapper_PFGE Manual.pdf. Accessed 3 Mar 2016.

25. Pearson WR, Wood T, Zhang Z, Miller W. Comparison of DNA sequences with protein sequences. Genomics. 1997:46:24-36.

26. Martin M. Cutadapt removes adapter sequences from high-throughput sequencing reads. EmbNET J. 2011;17:10-2.

27. CLCBio Genomic Workbench NGS pipeline. https://www.qiagenbioinformatics.com/. 3 Mar 2016

28. Thermo Scientific: Assessment of Nucleic Acid Purity. In T-042 Technical Biulletin. http://www.nanodrop.com/Library/T042-NanoDrop-Spectrophotometers-Nucleic-Acid-Purity-Ratios.pdf. Accessed 3 Mar 2016.

29. Goodwin S, Gurtowski J, Ethe-Sayers S, Deshpande P, Schatz MC, McCombie WR. Oxford Nanopore sequencing, hybrid error correction, and de novo assembly of a eukaryotic genome. Genome Res. 2015;25:1750-6.

30. Rhoads A, Au KF. PacBio sequencing and its applications. Genomics Proteomics Bioinform. 2015;13:278-89.

31. Chakraborty M, Baldwin-Brown JG, Long AD, Emerson JJ. Contiguous and accurate de novo assembly of metazoan genomes with modest long read coverage. Nucleic Acids Res. 2016;2(44):e147.

32. Ciniselli CM, Pizzamiglio S, Malentacchi F, Gelmini S, Pazzagli M, Hartmann CC. Combining qualitative and quantitative imaging evaluation for the assessment of genomic DNA integrity: the SPIDIA experience. Anal Biochem. 2015;479:60-2.

33. Malentacchi F, Ciniselli CM, Pazzagli M, Verderio P, Barraud L, Hartmann CC, et al. Influence of pre-analytical procedures on genomic DNA integrity in blood samples: the SPIDIA experience. Clin Chim Acta. 2015;2:205-10.

34. Illumina: Quality Scores for Next-Generation Sequencing. Assessing sequencing accuracy using Phred quality scoring. In Technical Note: Sequencing. 2011;1-2

35. Knauf $U$, Hachtel W. The genes encoding subunits of ATP synthase are conserved in the reduced plastid genome of the heterotrophic alga Prototheca wickerhamii. Mol Genet Genomics. 2002;267:492-7.

36. Tourasse NJ, Shtaida N, Khozin-Goldberg I, Boussiba S, Vallon O. The complete mitochondrial genome sequence of the green microalga Lobosphaera (Parietochloris) incisa reveals a new type of palindromic repetitive repeat. BMC Genomics. 2015;16:580.

37. Lutz KA, Wang W, Zdepski A, Todd PM. Isolation and analysis of high quality nuclear DNA with reduced organellar DNA for plant genome sequencing and resequencing. BMC Biotechnol. 2011;11:54.

\section{Submit your next manuscript to BioMed Central and we will help you at every step:}

- We accept pre-submission inquiries

- Our selector tool helps you to find the most relevant journal

- We provide round the clock customer support

- Convenient online submission

- Thorough peer review

- Inclusion in PubMed and all major indexing services

- Maximum visibility for your research

Submit your manuscript at www.biomedcentral com/submit

Ciomed Central 